\title{
SIMULAÇÃO DA DERIVA DE CLOMAZONE E GLYPHOSATE EM MUDAS DE LARANJEIRA 'HAMLIN'
}

\author{
EDUARDO REVOREDO FORESTI ${ }^{2}$, MARILUCE PASCOINA NEPOMUCENO ${ }^{3}$, \\ PEDRO LUIS DA COSTA AGUIAR ALVES ${ }^{4}$
}

RESUMO- Na região citrícola do Estado de São Paulo, é comum que a cultura da laranja e da cana-deaçúcar seja vizinha. Por propiciar uma redução de custos, o setor sucroalcooleiro vem procurando otimizar suas aplicações, como, por exemplo, por meio das aplicações aéreas, prática que aumenta o risco de deriva de produtos em culturas não alvo. Objetivou-se neste trabalho avaliar os danos causados pela deriva de clomazone, na sequência da deriva de glyphosate, sobre o crescimento de plantas jovens de laranjeira 'Hamlin'. $\mathrm{O}$ delineamento experimental utilizado foi o inteiramente casualizado, com os tratamentos dispostos em esquema fatorial $2 \times 8$, sendo dois herbicidas (clomazone isolado e glyphosate a $0,75 \%$ p.c. + clomazone) e oito doses crescentes do clomazone $(0 ; 1,56 ; 3,12 ; 6,25 ; 12,50 ; 18,75 ; 25,00$ e $50,00 \%$ da dose recomendada comercialmente para o controle de plantas daninhas), com 3 repetições. As avaliações foram compostas por diâmetro do caule, comprimento dos ramos e teor relativo de clorofila total, determinados dos 10 aos 90 dias após a aplicação (DAA), e área foliar, matéria seca de folhas e caule, determinados aos 90 DAA. Os resultados obtidos indicaram que houve redução significativa nas características avaliadas, sendo que os efeitos negativos para a cultura ocorrem mesmo em doses baixas $(1,56 \%)$, que foram capazes de prejudicar o crescimento das plantas. Os resultados obtidos permitem concluir que a deriva de clomazone isolado ou sem sequência do glyphosate causa prejuízos no crescimento inicial das laranjeiras, atuando de forma mais agressiva quando em sequência com a deriva de glyphosate.

Termos para indexação: fitotoxicidade, Citrus, herbicidas.

\section{DRIFT SIMULATION OF CLOMAZONE AND GLYPHOSATE IN ORANGE 'HAMLIN' SEEDLINGS}

\begin{abstract}
In citrus area of the State of São Paulo it is common that the orange and the sugar cane crops are neighboring. To provide a cost reduce, alcohol and sugar sectors are looking for optimizing their applications, for example, by aerial applications, a practice that increases the risk of drifting of these products in non-target crops. Therefore, this study aimed to evaluate the effects caused by drift simulation of clomazone, itself or followed by glyphosate application in the growth of young plants of orange 'Hamlin'. The experimental design was randomized blocks with treatments arranged in a $2 \times 8$ factorial design, the treatments consisting of two herbicides (clomazone isolated and glyphosate $0.75 \% \mathrm{pc}+$ clomazone) and eight increasing doses of clomazone $(0,1.56,3.12,6.25,12.50,18.75,25.00$ and $50.00 \%$ of the recommended rate for weed control) with three replicates. At 10 and 90 days after application (DAA) were evaluated stem diameter, length of the branches and the total chlorophyll content, and at 90 DAA were also evaluated leaf area, dry matter of leaves and stem. The results indicated that there was significant reduction in the evaluated characteristics, and the negative effects occur even at low doses at the crop $(1,56 \%)$, that were able to damage the culture growth. From the results obtained in this study, it can be concluded that the drift of clomazone alone or without following the glyphosate causes losses in the initial growth of the orange, acting more aggressively when in sequence with glyphosate drift.
\end{abstract}

Index terms: phytotoxicity, Citrus, herbicides.

\footnotetext{
${ }^{1}$ (Trabalho 043-14). Recebido em:12-02-2014. Aceito para publicação em: 23-02-2015.

${ }^{2}$ Graduando em Agronomia - FCAV/UNESP. E-mail: duforesti@yahoo.com.br

${ }^{3}$ Eng. Agr., Pós-Doutoranda - FCAV/UNESP. E-mail: mariluce_n@hotmail.com

${ }^{4}$ Eng.Agr., Prof. Adjunto. Faculdade de Ciências Agrárias e Veterinárias - FCAV/UNESP, Departamento de Biologia Aplicada,

Laboratório de Plantas Daninhas (LAPDA). E-mail: plalves@fcav.unesp.br
} 


\section{INTRODUÇ̃̃O}

Na região citrícola do Estado de São Paulo, a erradicação de pomares coincidiu principalmente com a expansão das áreas de plantio de cana-de-açúcar, fazendo com que uma cultura fosse substituída por outra ou se tornassem, frequentemente, vizinhas (TIMOSSI; ALVES, 2001a).

O setor sucroalcooleiro vem procurando aperfeiçoar suas aplicações de defensivos como forma de reduzir despesas e aumentar a eficiência. Uma das formas de otimização é por meio das aplicações aéreas, que vêm sendo muito utilizadas para herbicidas e maturadores, mas que aumenta o risco de deriva desses produtos em culturas não alvo (GANDOLFO et al., 2013). O dano causado por deriva de herbicida é reconhecido como um problema em muitas áreas (TAKAHASHI et al., 2009; OLIVEIRA et al., 2013). O grau de injúria e os sintomas observados são afetados por fatores como a espécie, o estádio de desenvolvimento da planta, o clima, o mecanismo de ação e a dose do herbicida (AL-KHATIB et al.,2003).

Os herbicidas que mais frequentemente ocasionam danos em plantas frutíferas, em decorrência da deriva e/ou da má aplicação, são o clomazone e o glyphosate, tendo maior frequência de aplicação nos meses de setembro e outubro, coincidindo com a floração e a formação dos frutos nas laranjeiras. Nesses pomares, ocasionalmente, são observados sintomas cloróticos e necróticos nas folhas das plantas, causados provavelmente pelo efeito de deriva do clomazone, provenientes da aplicação na cana-de-açúcar. Este fato é agravado pelas aplicações intensivas, durante o período pré e pós-plantio da cana-de-açúcar, realizados mecanicamente com uso de tratores, o que aumenta a possibilidade de derivas. Timossi e Alves (2001b) relataram que a dose comercial do clomazone resultou na formação de manchas cloróticas e/ou necróticas na casca do fruto de laranja e causou a mortalidade dos ramos que se encontravam em crescimento vegetativo. Em outro trabalho, Timossi e Alves (2001a) observaram que a deriva de clomazone, em mistura com ametrina, em plantas sadias de laranjeira 'Hamlin' de quatorze anos, provocou a queda prematura de folhas, morte de ramos, formação de manchas necróticas nos frutos, leve redução no diâmetro e aborto de frutos, quando as plantas foram submetidas a concentrações próximas à dose comercial para cana-de-açúcar.

Existem relatos e reclamações de produtores sobre possíveis efeitos da deriva de glyphosate quando usado como maturador ou de sua má aplicação em pomares, quando usado como herbicida, cujos efeitos fitotóxicos podem ocorrer isolados (GRAVENA et al., 2009; 2012) ou em associação com outros herbicidas aplicados posteriormente, como é o caso do clomazone.

Constatada a carência de pesquisas sobre os efeitos de deriva de herbicidas, principalmente em plantas jovens de laranjeira, foi estabelecido este trabalho com o objetivo de avaliar os danos causados pela deriva de clomazone, na sequência da deriva de glyphosate, sobre o crescimento de plantas jovens de laranjeira 'Hamlin'.

\section{MATERIAL E MÉTODOS}

Foram utilizadas quarenta e oito mudas de laranjeira, com copa 'Hamlin' (Citrus sinensis L. Osbeck cv. Hamlin) enxertada em Limão-Cravo, que estavam, em média, com 48,0 $\pm 0,1 \mathrm{~cm}$ de altura e $9,1 \pm 0,48 \mathrm{~mm}$ de diâmetro de caule, medido a $5 \mathrm{~cm}$ acima da superfície do solo e teor relativo de clorofila total $(97,20 \pm 2,07)$, determinado com clorofilômetro Minolta, mode SPAD 502.

Os tratamentos experimentais constaram da aplicação de doses crescentes de clomazone, isolado ou em sequência com a de glyphosate, as quais atingiram metade da dose recomendada comercialmente para o controle de plantas daninhas, com uma testemunha sem aplicação (Tabela 1).

Primeiramente, a aplicação do glyphosate (Glizmax - 480 g e.a. $\mathrm{L}^{-1}$ ), na concentração de $0,75 \%$ da dose comercial recomendada pelo fabricante, ocorreu em 24 mudas de laranjeira, restando 24 mudas sem aplicação de produto, que foram utilizadas para aplicação das doses de clomazone isolado. A aplicação do herbicida foi realizada com pulverizador costal à pressão constante $\left(\mathrm{CO}_{2}\right)$, munido de barra com quatro bicos XR11002, espaçados a cada 0,5 m, e regulado para um gasto de volume de calda de 200 $\mathrm{L} \mathrm{ha}^{-1}$. Após 15 dias, houve a aplicação das subdoses crescentes de clomazone (Gamit - 500 g i.a. L $\left.{ }^{-1}\right),(24$ plantas já aplicadas com glyphosate e 24 plantas de tratamento isolado), sendo cada subdose aplicada em três plantas, utilizando o mesmo procedimento da primeira aplicação.

As mudas foram mantidas nos recipientes originais (sacos plásticos) por um mês, para o início das brotações, condução inicial da formação da copa, em três pernadas, e aplicação dos tratamentos. Um dia após a aplicação de clomazone, as mudas foram plantadas em vasos com capacidade para 20 L, preenchidos com solo coletado na camada arável de um Latossolo Vermelho-Escuro previamente adubado e dispostos segundo o delineamento experimental inteiramente casualizado, com três 
repetições e uma planta por parcela.

No decorrer do período experimental, além da irrigação periódica das plantas, foram adotadas todas as práticas necessárias para a manutenção das boas condições sanitárias das plantas, sendo efetuada a aplicação de deltametrina, na dose de $30 \mathrm{~mL}$ p.c. $100 \mathrm{~L}^{-1}$ de água, para o controle de pulgão e larvaminadora, de acordo com o monitoramento de pragas. Aos 45 dias após a aplicação do clomazone, foi realizada uma adubação nitrogenada, adicionando-se $50 \mathrm{~mL} \mathrm{vaso}^{-1}$ de ureia a $0,5 \%$.

Foram feitas avaliações aos $10 ; 20 ; 30 ; 40 ; 50$; 60 e 90 dias após a aplicação (DAA) do clomazone quanto ao diâmetro do caule (a $5 \mathrm{~cm}$ acima da linha de enxertia, com auxílio de paquímetro digital), comprimento do ramo (considerando um dos ramos de pernada previamente marcado com fitilho) e teor relativo de clorofila total (UR, Minolta, mode SPAD 502). A determinação do teor relativo de clorofila total foi feita em duas folhas por planta, sendo uma previamente marcada na porção mediana da planta, e outra localizada no ponteiro, e estabelecida a média entre elas.

Aos 90 DAA, todas as plantas foram cortadas a $5 \mathrm{~cm}$ acima do solo e, além das características anteriormente citadas, foram determinadas: área foliar (com auxílio do aparelho Li Cor modelo Li 3000A) e massa seca do caule e das folhas (ambas obtidas após a secagem dos materiais em estufa com circulação forçada de ar a $70^{\circ} \mathrm{C}$ até massa constante).

Os dados avaliados foram submetidos à análise de variância, pelo teste $\mathrm{F}$, e as médias, comparadas pelo teste de Tukey, a 5\% de probabilidade de erro, utilizando o programa estatístico Estat.

\section{RESULTADOS E DISCUSSÃO}

Após quinze dias da aplicação do glyphosate, observou-se que as mudas de laranjeira não apresentavam diferenças quanto às características de diâmetro do caule e teor relativo de clorofila total, quando comparados os tratamentos com ou sem glyphosate (Tabela 2). Para o comprimento do ramo, verificou-se diferença significativa, sendo que as plantas tratadas com glyphosate apresentaram ramos 45\% mais curtos do que as não tratadas.

Já aos 10 dias após a aplicação do clomazone (DAA), verificou-se que todas as plantas que receberam glyphosate possuíam ramos mais curtos que os da testemunha (Figura 1A), sendo que as plantas do tratamento com $50 \%$ de clomazone possuíam ramos com menos de $10 \mathrm{~cm}$ de comprimento, enquanto os da testemunha estavam com $25 \mathrm{~cm}$. No decorrer do período, os tratamentos com 1,56\%,
$3,12 \%, 6,25 \%$ e $25 \%$ de clomazone resultaram em menor interferência do herbicida, mantendo o crescimento superior quando comparado aos demais tratamentos.

Comparando os tratamentos nas plantas sem a aplicação do glyphosate (Figura 1B), observase que, aos 10 DAA, a testemunha apresentava comprimento de ramo em torno de $25 \mathrm{~cm}$, sendo superior aos tratamentos com $12,50 \%, 18,75 \%$ e $50 \%$ de clomazone, e inferior aos demais tratamentos. No geral, o comprimento do ramo no tratamento com $1,56 \%$ foi superior a todos os tratamentos, inclusive a testemunha. As plantas que receberam o tratamento com $25,00 \%$ mantiveram comprimento de ramo semelhante ao da testemunha, mas após 50 dias da aplicação a testemunha apresentou crescimento de ramo superior. Aos 90 DAA, não se constatou efeito significativo da interação entre glyphosate e as doses de clomazone (Tabela 3). Verificou-se apenas que as plantas tratadas previamente com glyphosate apresentaram ramos $20 \%$ mais curtos do que as não tratadas, independentemente da dose de clomazone, enquanto as doses não diferiram entre si, independentemente do glyphosate, embora haja uma tendência de redução no comprimento do ramo com o aumento da dose.

Gravena et al. (2012) estudaram o efeito de doses de glyphosate aplicadas no caule $(0 ; 90 ; 18$; $260 ; 540 ; 1.080$ e $2.160 \mathrm{~g}$ e.a. $\left.\cdot \mathrm{ha}^{-1}\right)$ e nas folhas $\left(0 ; 0.036 ; 0.36 ; 3.6 ; 36 ; 360\right.$ e 720 g e.a. $\left.\cdot h^{-1}\right)$ de laranjeiras 'Valência' (Citrus sinensis L. Osbeck) enxertadas em limão-cravo (Citrus limonia L. Osbeck) com 27 meses, e 'Valência' enxertadas em citrumelo (Poncirus trifoliata (L.) Raf x Citrus paradisi Macf), com 20 meses. Os autores não observaram efeito visual do glyphosate quando a aplicação foi feita no caule, mas as plantas foram afetadas com aplicações foliares com doses a partir de $360 \mathrm{~g}$ e.a. ha $^{-1}$. O principal sintoma foi observado nas brotações, demonstrando efeito nos meristemas. Pouco ou nenhum efeito foi observado em folhas maduras. Todas as plantas afetadas pelo glyphosate recuperaram-se entre 6 e 12 meses após a aplicação, demonstrando que o glyphosate tem baixa toxicidade para laranjeiras em doses de $360 \mathrm{~g}$ e.a. $\mathrm{ha}^{-1}$. Na presente pesquisa, a aplicação de $0,75 \%$ da dose comercial de glyphosate, correspondendo a $72 \mathrm{~g}$ e.a. $\mathrm{ha}^{-1}$, resultou, além do retardo no crescimento dos ramos, na superbrotação das gemas, com emissão de mais folhas e/ou ramos.

Outras pesquisas com plantas perenes relatam enrugamento ou má-formação de folhas (especialmente nas áreas de rebrota) e necrose de meristema (TAKAHASHI et al., 2009; GANDOLFO 
et al., 2013). Em contraste com muitos herbicidas de contato, os sintomas fitotóxicos de danos pelo glyphosate geralmente se desenvolvem lentamente, com a morte ocorrendo após vários dias e mesmo semanas. Para frutíferas, em geral, aplicações de glyphosate em folhagens são mais prejudiciais às plantas jovens e aos tecidos, do que para as plantas maduras. Devido ao longo tempo requerido, a estabilidade in vivo do glyphosate é uma importante característica que contribui para seus efeitos fitotóxicos irreversíveis. Nas plantas, o glyphosate é muito estável, com pequena degradação detectável ocorrendo em longo período de tempo (CARVALHO et al., 2012). Para troncos danificados, o glyphosate causa a formação de calos. Os sintomas em brotos que cresceram após a aplicação do herbicida podem persistir por até 2 anos, após o qual as plantas podem retomar o crescimento normal (TOTH; MORRISON, 1977).

Comparando os tratamentos nas plantas em que foi aplicado glyphosate (Figura 2A), observou-se que o diâmetro do caule da testemunha se manteve superior ao dos demais tratamentos entre os 25 e 50 DAA. As plantas que receberam o tratamento de $3,12 \%$ de clomazone, após os 50 DAA, apresentaram crescimento superior ao de todas as outras doses, com aproximadamente $14 \mathrm{~mm}$ de diâmetro aos 90 dias após a aplicação. As plantas que receberam a dose de $50 \%$ de clomazone apresentaram diâmetro de caule inferior aos dos outros tratamentos, com aproximadamente $12 \mathrm{~mm}$ de diâmetro.

Nas plantas sem a aplicação do glyphosate (Figura 2B), foi observado que o caule da testemunha obteve crescimento em diâmetro superior ao dos demais tratamentos, a partir dos 20 dias após a aplicação, mantendo-se superior até os 90 dias após a aplicação. Porém, as plantas que receberam $6,25 \%$ de clomazone, a partir dos 40 dias após a aplicação, apresentaram elevado desenvolvimento do diâmetro do caule, e aos 90 dias equipararam-se ao da testemunha. As plantas com 50\% da dose do clomazone apresentaram, aos 90 DAA, diâmetro de caule inferior aos demais. Aos 90 DAA não se observou efeito do glyphosate no diâmetro dos ramos, independentemente das doses de clomazone (Tabela 3), mas as plantas tratadas com as doses de 25 e $50 \%$ de clomazone apresentaram ramos com menor diâmetro, independentemente do glyphosate. Pavan (2011) também constatou que as laranjeiras 'Hamlin' que receberam o clomazone tiveram redução da taxa de crescimento do diâmetro do caule, avaliada aos 60 DAA.

Durante o experimento, foi observado, nas plantas tratadas com glyphosate, que o teor de clorofila total nas plantas-testemunha foi superior ao das plantas que receberam as doses de $25 \%$ e 50\% de clomazone (Figura 3A). Após 45 DAA, devido à deficiência de nitrogênio, foram aplicados $5 \mathrm{~g} \mathrm{~L}^{-1}$ de ureia em todas as plantas. Verificou- se que todas as plantas apresentaram recuperação nos valores dos teores de clorofila total entre os 50-60 DAA, mas mantendo suas diferenças. Isso se deve à abscisão das folhas mais afetadas pelo clomazone e ao desenvolvimento de novas folhas, e à recuperação das folhas que não sofreram tanto com a aplicação do produto.

O teor relativo de clorofila total nas plantas nas quais não foi aplicado glyphosate (Figura 3B), de modo geral, apresentou comportamento semelhante até os 40 DAA do clomazone. Após os 45 DAA, a testemunha manteve seu teor foliar praticamente constante, enquanto as plantas que receberam as diversas doses de clomazone tiveram redução nos teores de clorofila total. Entre os 50 e 60 DAA, foi observado o início da recuperação dos teores de clorofila total, decorrente da aplicação de ureia, porém sem atingir os valores iniciais, como havia sido observado na condição com a aplicação do glyphosate. Aos 90 DAA, as plantas tratadas com glyphosate apresentaram maior teor de clorofila nas folhas do que as não tratadas, independentemente das doses de clomazone (Tabela 3), enquanto a dose de $50 \%$ do clomazone reduziu o teor de clorofila, independentemente do glyphosate, com tendência de redução nas demais doses quando comparadas à testemunha.

O clomazone normalmente reduz os teores de clorofilas na planta, uma vez que seu mecanismo de ação é inibir a síntese de clorofilas, e os sintomas manifestam-se primeiro nas folhas dos ponteiros, pois a absorção do herbicida ocorre preferencialmente pelo meristema apical da planta, e sua translocação ocorre pelo xilema, seguindo o fluxo transpiracional (RODRIGUES; ALMEIDA, 2011). A clorose foliar em citros manifesta-se rapidamente, antes dos 7 DAA (TIMOSSI; ALVES, 2001b; PAVAN, 2011), em consequência da foto-oxidação e destruição da clorofila, provocada pela presença de luz e ausência de carotenoides, que exercem seu papel protetor contra a foto-oxidação (TAKAHASHI et al., 2009).

Em relação à área foliar, não foi observado efeito significativo da aplicação do glyphosate (Tabela 4). Comparando os efeitos de doses do clomazone, independentemente das doses de glyphosate, observou-se efeito significativo, sendo que as plantas da testemunha apresentaram maior área foliar quando comparadas às tratadas com clomazone, que, por sua vez, não diferiram entre si, 
ou seja, a dose de 1,56\% de clomazone já causou redução significativa. A interação entre a aplicação do glyphosate e as doses do clomazone não foi significativa.

A deriva do clomazone proporcionou manchas cloróticas e necróticas em folhas novas e velhas e, posteriormente, a abscisão de grande parte, influenciando na área foliar após 90 dias da aplicação. Timossi e Alves (2001b) constataram que a aplicação de 2,0 L ha ${ }^{-1}$ de clomazone em laranjeira 'Hamlin' ocasionou queda de folhas ou estas entraram em processo de senescência, após se tornarem cloróticas. Kruse et al. (2001) relataram sintomas semelhantes para as culturas de milho, amendoim e algodão.

Em relação à matéria seca das folhas, aos 90 DAA, também não foi observado efeito significativo da aplicação do glyphosate e da interação entre a aplicação do glyphosate e as doses de clomazone
(Tabela 4). Houve apenas efeito significativo para o clomazone, sendo que a massa seca das folhas da testemunha foi superior a todas as plantas tratadas com o herbicida, já a partir de $1,56 \%$, sem haver diferença entre os efeitos das doses.

Também não foi observado efeito significativo da aplicação do glyphosate e da interação entre a aplicação do glyphosate e doses de clomazone, sobre a matéria seca do caule, aos 90 DAA (Tabela 4). Novamente se observou efeito significativo de clomazone, sendo a massa seca do caule das plantastestemunha superior ao das tratadas, à exceção das doses de $3,12 \%$ e $6,25 \%$, que não diferenciaram entre si e apresentaram mais massa seca de caule que as tratadas com a dose de 50\% de clomazone. Pavan (2011) observou redução linear na matéria seca dos ramos, caule e folhas de laranjeiras 'Hamlin' com o aumento da dose de clomazone.

TABELA 1 - Descrição dos tratamentos experimentais, com as respectivas doses dos ingredientes ativos (i.a.) dos produtos.

\begin{tabular}{|c|c|c|c|}
\hline \multirow{2}{*}{ Tratamentos } & \multicolumn{2}{|c|}{ Dose } & \multirow{2}{*}{$\begin{array}{c}\text { Concentração } \\
(\% \mathrm{v} / \mathrm{v})\end{array}$} \\
\hline & i.a./e.a. $\left(\mathrm{kg} \cdot \mathrm{ha}^{-1}\right)$ & p.c. $\left(\mathrm{kg}\right.$ ou L.ha $\left.{ }^{-1}\right)$ & \\
\hline 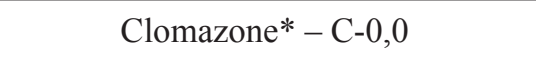 & 0 & 0 & 0 \\
\hline Clomazone - C-1,56 & 0,015 & 0,031 & 1,06 \\
\hline Clomazone - C-3,12 & 0,031 & 0,062 & 3,12 \\
\hline Clomazone - C- 6,25 & 0,062 & 0,0125 & 6,25 \\
\hline Clomazone $-\mathrm{C}-12,50$ & 0,125 & 0,250 & 12,50 \\
\hline Clomazone - C-18,75 & 0,187 & 0,2625 & 18,75 \\
\hline Clomazone - C-25,00 & 0,250 & 0,500 & 25,00 \\
\hline Clomazone - C-50,00 & 0,500 & 1,000 & 50,00 \\
\hline Clomazone $-\mathrm{C}-0,0+$ Glyphosate** & $0,000+0,072$ & $0,00+0,150$ & $0,00+0,75$ \\
\hline Clomazone - C-1,56 + Glyphosate & $0,015+0,072$ & $0,031+0,150$ & $1,06+0,75$ \\
\hline Clomazone $-\mathrm{C}-3,12+$ Glyphosate & $0,031+0,072$ & $0,062+0,150$ & $3,12+0,75$ \\
\hline Clomazone - C-6,25 + Glyphosate & $0,062+0,072$ & $0,0125+0,150$ & $6,25+0,75$ \\
\hline Clomazone - C-12,50 + Glyphosate & $0,125+0,072$ & $0,250+0,150$ & $12,50+0,75$ \\
\hline Clomazone - C-18,75 + Glyphosate & $0,187+0,072$ & $0,2625+0,150$ & $18,75+0,75$ \\
\hline Clomazone - C-25,00 + Glyphosate & $0,250+0,072$ & $0,500+0,150$ & $25,00+0,75$ \\
\hline Clomazone - C-50,00 + Glyphosate & $0,500+0,072$ & $1,000+0,150$ & $50,00+0,75$ \\
\hline
\end{tabular}

*Gamit (Concentração 500g)** Glizmax (Concentração 480g e.a.) 
TABELA 2 - Comprimento do ramo, diâmetro do caule e teor relativo de clorofila total em laranjeira 'Hamlin' aos 15 dias após a aplicação do glyphosate (média \pm erro- padrão).

\begin{tabular}{lccc}
\hline Tratamentos & Comprimento do ramo $\mathbf{( c m )}$ & Diâmetro $(\mathbf{m m})$ & Teor de clorofila \\
\hline Com glyphosate & $8,3 \pm 3,1 \mathrm{~b}$ & $9,5 \pm 0,5 \mathrm{a}$ & $94,0 \pm 2,4 \mathrm{a}$ \\
Sem glyphosate & $15,2 \pm 3,2 \mathrm{a}$ & $9,6 \pm 0,6 \mathrm{a}$ & $93,0 \pm 3,0 \mathrm{a}$ \\
\hline
\end{tabular}

Médias seguidas de mesma letra na coluna não diferem pelo teste $\mathrm{F}$, a $5 \%$ de probabilidade de erro.

TABELA 3 - Comprimento do ramo, diâmetro do caule e teor de clorofila total das mudas de laranjeira 'Hamlin' 90 dias após a aplicação dos tratamentos.

\begin{tabular}{|c|c|c|c|c|}
\hline HERBICIDAS & Dose $(\%)$ & Comprimento do ramo $(\mathrm{cm})$ & Diâmetro do caule (mm) & $\begin{array}{l}\text { Teor de } \\
\text { clorofila }\end{array}$ \\
\hline \multirow{2}{*}{ Glyphosate } & sem & $33,50 \mathrm{~A}$ & $12,92 \mathrm{~A}$ & $58,39 \mathrm{~B}$ \\
\hline & com & $27,00 \mathrm{~B}$ & $12,74 \mathrm{~A}$ & $83,18 \mathrm{~A}$ \\
\hline \multirow{8}{*}{ Clomazone } & 0,00 & $38,00 \mathrm{~A}$ & $13,08 \mathrm{AB}$ & $91,95 \mathrm{~A}$ \\
\hline & 1,56 & $36,00 \mathrm{~A}$ & $12,95 \mathrm{AB}$ & $74,75 \mathrm{AB}$ \\
\hline & 3,12 & $33,16 \mathrm{~A}$ & $13,82 \mathrm{~A}$ & $75,93 \mathrm{AB}$ \\
\hline & 6,25 & $32,66 \mathrm{~A}$ & $13,24 \mathrm{~A}$ & $76,58 \mathrm{~A}$ \\
\hline & 12,50 & $26,25 \mathrm{~A}$ & $12,88 \mathrm{AB}$ & $77,88 \mathrm{~A}$ \\
\hline & 18,75 & $25,08 \mathrm{~A}$ & $13,22 \mathrm{~A}$ & $63,10 \mathrm{AB}$ \\
\hline & 25,00 & $29,16 \mathrm{~A}$ & 11,79 B & $62,68 \mathrm{AB}$ \\
\hline & 50,00 & $21,66 \mathrm{~A}$ & $11,68 \mathrm{~B}$ & $43,41 \mathrm{~B}$ \\
\hline \multicolumn{2}{|c|}{$\mathbf{F}_{\text {herbicidas }}$} & $5,14 *$ & $0,68 \mathrm{NS}$ & $24,05 * *$ \\
\hline \multicolumn{2}{|l|}{$\mathbf{F}_{\text {doses }}$} & $1,95 \mathrm{NS}$ & $5,77 * *$ & $4,04 * *$ \\
\hline \multicolumn{2}{|c|}{$\mathbf{F}_{\text {herbicidasxdoses }}$} & $0,19 \mathrm{NS}$ & $0,68 \mathrm{NS}$ & $1,14 \mathrm{NS}$ \\
\hline \multicolumn{2}{|c|}{ CV (\%) } & 32,80 & 5,84 & 24,73 \\
\hline
\end{tabular}

Médias seguidas de mesma letra na coluna não diferem pelo teste de Tukey, a $5 \%$ de probabilidade de erro. NS - não significativo; * significativo a $5 \%$ e a ** $1 \%$ pelo Teste $\mathrm{F}$.

TABELA 4- Área foliar, matéria seca das folhas (MSF) e matéria seca do caule (MSC) das mudas de laranjeira "Hamlin" aos 90 dias após a aplicação dos tratamentos.

\begin{tabular}{|c|c|c|c|c|}
\hline Herbicidas & Doses (\%) & Área foliar $\left(\mathrm{cm}^{2}\right)$ & MSF (g) & MSC (g) \\
\hline \multirow{2}{*}{ Glyphosate } & sem & $2061,90 \mathrm{~A}$ & $22,45 \mathrm{~A}$ & $37,18 \mathrm{~A}$ \\
\hline & com & $1947,84 \mathrm{~A}$ & $21,99 \mathrm{~A}$ & $35,19 \mathrm{~A}$ \\
\hline \multirow{8}{*}{ Clomazone } & 0,00 & $3240,72 \mathrm{~A}$ & $39,65 \mathrm{~A}$ & $53,01 \mathrm{~A}$ \\
\hline & 1,56 & 1862,96 B & $20,95 \mathrm{~B}$ & $36,06 \mathrm{BC}$ \\
\hline & 3,12 & 2029,85 B & $21,58 \mathrm{~B}$ & $39,46 \mathrm{AB}$ \\
\hline & 6,25 & 2000,16 B & 19,37 B & $38,86 \mathrm{AB}$ \\
\hline & 12,50 & $1731,97 \mathrm{~B}$ & $19,62 \mathrm{~B}$ & $34,59 \mathrm{BC}$ \\
\hline & 18,75 & $2032,82 \mathrm{~B}$ & $22,65 \mathrm{~B}$ & $34,14 \mathrm{BC}$ \\
\hline & 25,00 & $1736,04 \mathrm{~B}$ & $19,62 \mathrm{~B}$ & $29,81 \mathrm{BC}$ \\
\hline & 50,00 & 1404,46 B & $14,28 \mathrm{~B}$ & $23,56 \mathrm{C}$ \\
\hline $\mathbf{F}_{\text {herbicidas }}$ & & $0,54 \mathrm{NS}$ & $0,07 \mathrm{NS}$ & $0,76 \mathrm{NS}$ \\
\hline $\mathbf{F}_{\text {doses }}$ & & $6,11^{* *}$ & $9,37 * *$ & $7,03 * *$ \\
\hline $\mathbf{F}_{\text {herbicidasxd }}$ & & $1,42 \mathrm{NS}$ & $1,68 \mathrm{NS}$ & $0,54 \mathrm{NS}$ \\
\hline CV (\%) & & 26,76 & 26,89 & 21,72 \\
\hline
\end{tabular}

Médias seguidas de mesma letra na coluna não diferem pelo teste de Tukey, a 5\% de probabilidade de erro. NS - não significativo; * significativo a $5 \%$ e a $* * 1 \%$ pelo teste $\mathrm{F}$. 

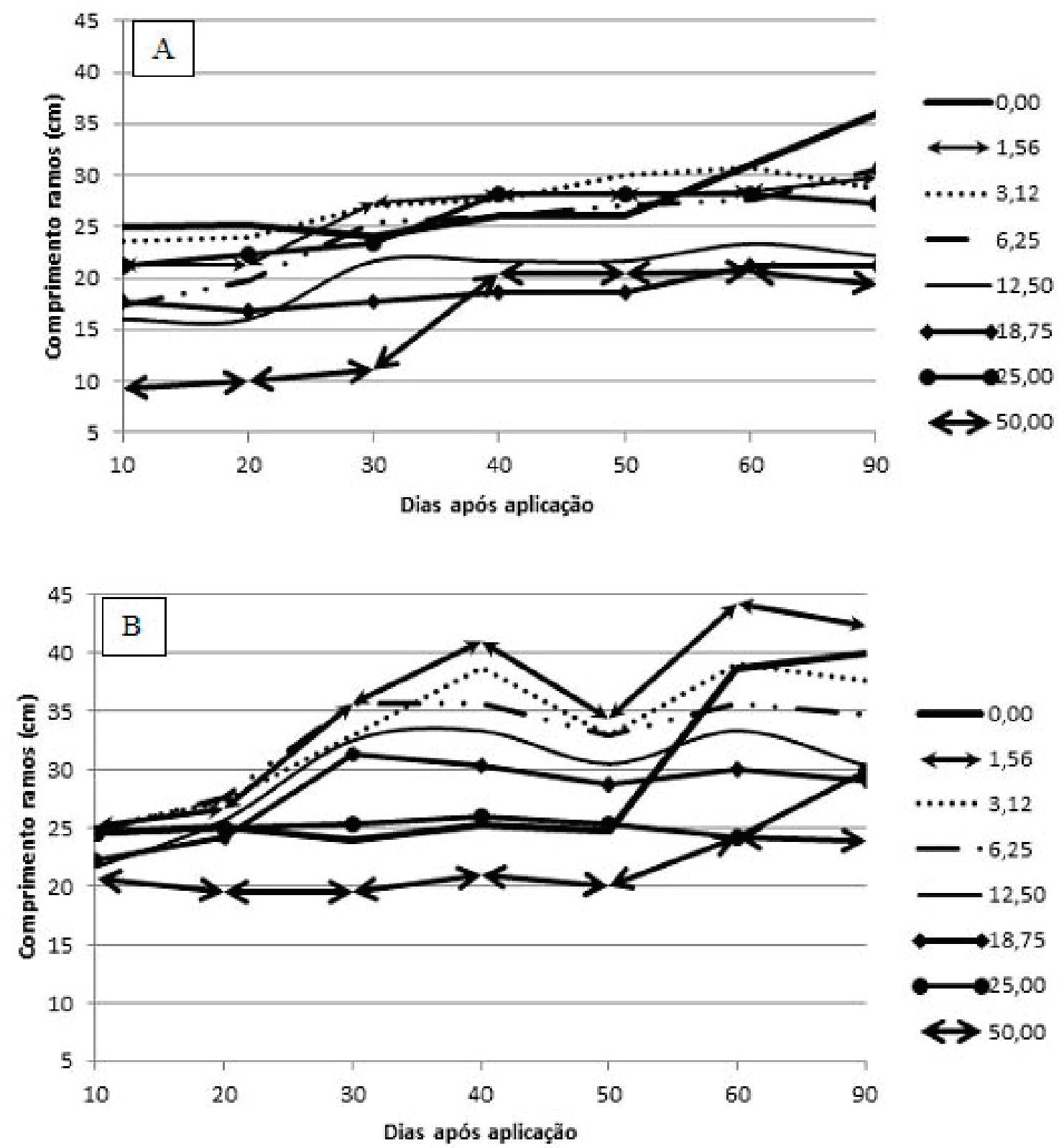

FIGURA 1- Comprimento dos ramos de laranjeira 'Hamlin' aos 10; 20; 30; 40; 50; 60 e 90 DAA dos tratamentos de clomazone, com (A) e sem (B) a aplicação do glyphosate. 

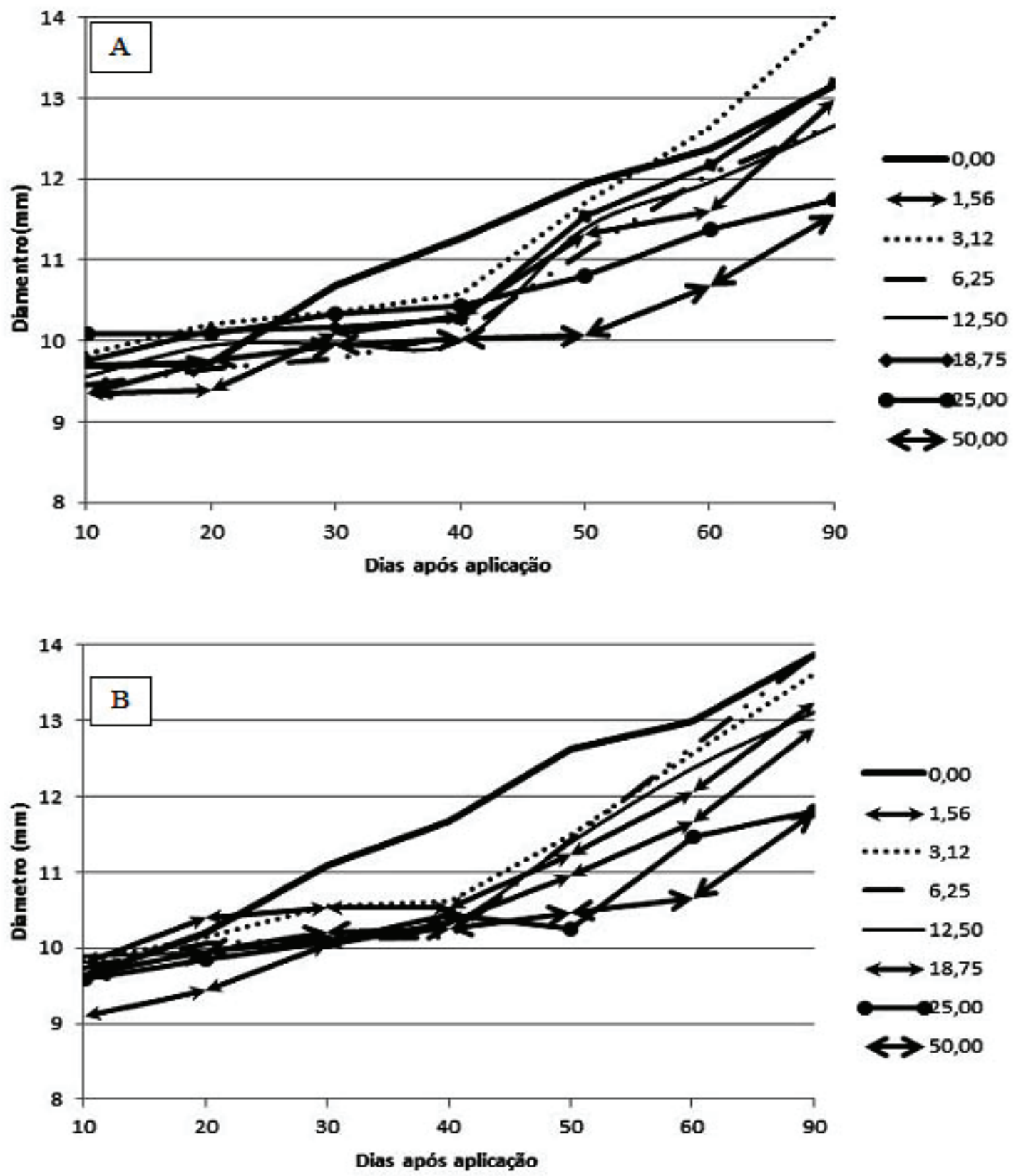

FIGURA 2 - Diâmetro dos ramos de laranjeira 'Hamlin' aos 10; 20; 30;40; 50; 60 e 90 DAA dos tratamentos de clomazone, com (A) e sem (B) a aplicação do glyphosate. 

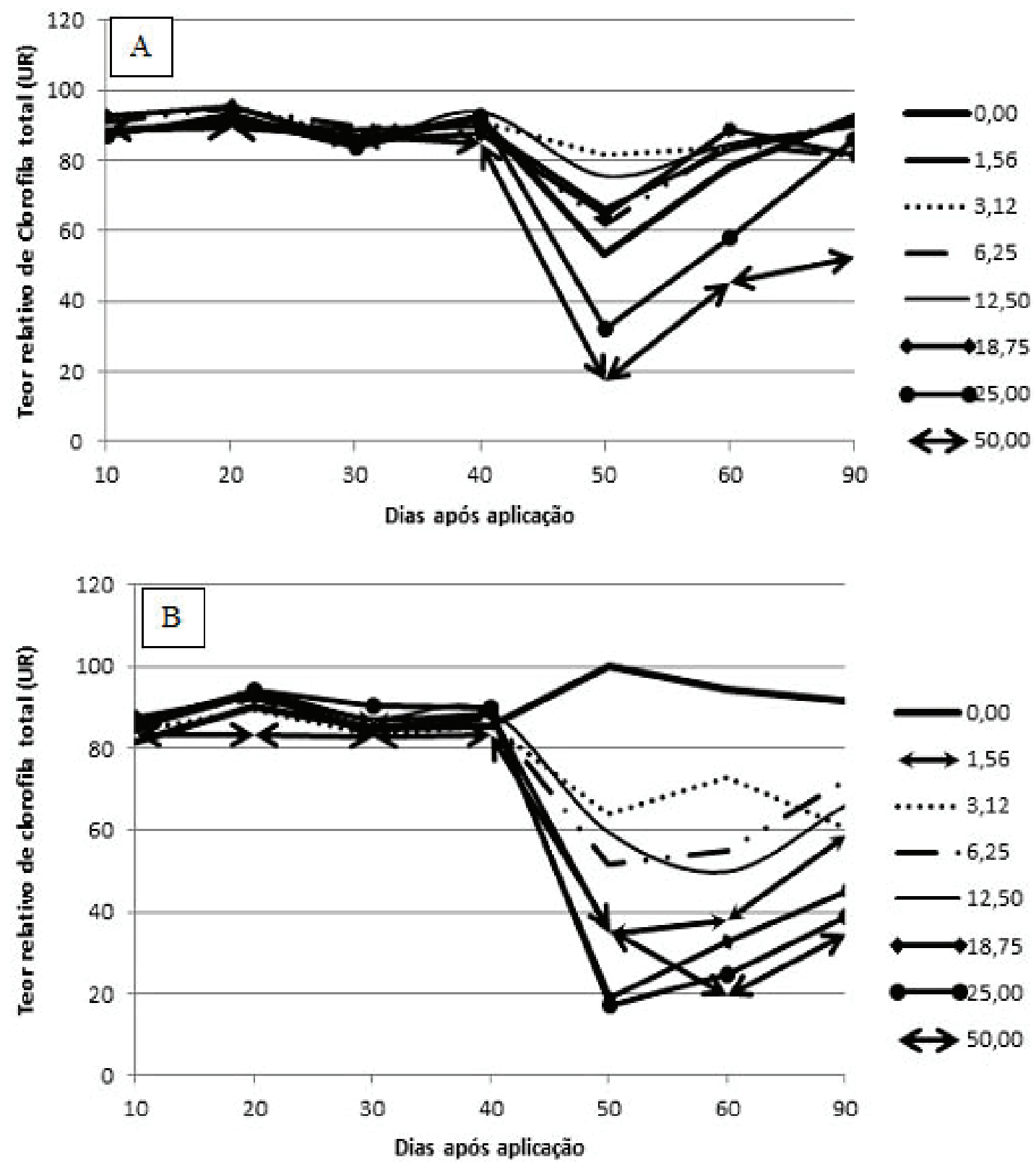

FIGURA 3 - Teor relativo de clorofila total (UR) em folhas de laranjeira 'Hamlin' aos 10; 20; 30;40; 50; 60 e 90 DAA dos tratamentos de clomazone, com (A) e sem (B) a aplicação do glyphosate.

\section{CONCLUSÃO}

Aderiva de clomazone prejudica o crescimento e o desenvolvimento inicial de laranjeiras 'Hamlin' já a partir de 1,56\% da dose comercial. Quando essa deriva ocorre após uma subdose de glyphosate $(0,75 \%$ do produto comercial), o efeito é mais acentuado, embora essa subdose do glyphosate não cause danos às plantas.

\section{AGRADECIMENTOS}

Foresti, E. R. e Alves, P.L.C.A. agradecem ao CNPq, pela concessão das bolsas de IC e PQ, respectivamente. 


\section{REFERÊNCIAS}

AL-KHATIB, K.; CLAASSEN, M.M.; GEIER, P.W.; DUNCAN, S.R.; STAHLMAN, P.W.; REGEHR, D.L.; HEER, W.F. Grain sorghum response to simulated drift from glufosinate, glyphosate, imazethapyr and sethoxydim. Weed Technology, Lawrence, v.17, n.2, p.261-265, 2003.

CARVALHO, L. B.; ALVES, P. L. C. A.; BIANCO, S.; PRADO, R. Physiological dose-response of coffee (Coffea arabica L.) plants to glyphosate depends on growth stage. Chilean Journal of Agricultural Research, Chillán, v. 72, p. 182-187, 2012.

GANDOlFo, M. A.; CheChetTo, R. G.; CARVALHO, F. K.; GANDOLFO, U. D.; MORAES, E. D. Influência de pontas de pulverização e adjuvantes na deriva em caldas com glyphosate. Revista Ciência Agronômica, Fortaleza, v. 44, n. 3, p. 474-480, 2013.

GRAVENA, R.; VICTÓRIA FILHO, R.; ALVES, P. L. C. A.; MAZZAFERA, P.; GRAVENA, A. R. Low glyphosate rates do not affect Citrus limonia (L.) Osbeck seedlings. Pest Management Science, New York, v. 65, p. 420-425, 2009.

GRAVENA, R.; VICTORIA FILHO, R.; ALVES, P. L. C. A.; MAZZAFERA, P.; GRAVENA, A. R. Glyphosate has low toxicity to citrus plants growing in the field. Canadian Journal of Plant Science, Ottawa, v. 92, p. 119-127, 2012.

KRUSE, N. D. et al. Sinergismo potencial entre herbicidas inibidores do fotossistema II e da síntese de carotenoides. Ciência Rural, Santa Maria, v.31, n.4, p.569-575, 2001.
OLIVEIRA, R. B.; ANTUNIASSI, U. R.; MOTA, A. A. B.; CHECHETTO, R. G. Potential of adjuvants to reduce drift in agricultural spraying. Engenharia Agrícola, Jaboticabal, v.34, n.5, p.986-992, 2013.

PAVAN, G. B. Simulação de deriva de clomazone e ametryna e crescimento de mudas de laranjeira "Hamlin". 2011. 77 f. Monografia (Trabalho de graduação em Agronomia) - Faculdade de Ciências Agrárias e Veterinárias, Universidade Estadual, Jaboticabal, 2011.

RODRIGUES, B. N.; ALMEIDA, F. S. Guia de herbicidas. Londrina: Grafmarke, 2011. 697 p.

TAKAHASHI, E. N.; AlVES, P. L. C. A.; SALGADO, T. P.; FARIAS, M. A.; SILVA, A. C.; BIAGIONI, B. T. Consequências da deriva de clomazone e sulfentrazone em clones de $E$. grandis x E. urophylla. Revista Árvore, Viçosa, MG, v. 33, p. 675-683, 2009.

TIMOSSI, P. C.; ALVES, P. L. C. A. Efeitos da deriva de clomazone, aplicado isoladamente ou em mistura com ametryn, sobre características produtivas de laranjeira "Hamlin". Planta Daninha, Viçosa, MG, v.19, n.2, p.295-304, 2001a.

TIMOSSI, P. C.; ALVES, P. L. C. A. Efeitos da simulação de deriva de clomazone em plantas de laranjeira 'Hamlin'. Revista Brasileira de Fruticultura, Jaboticabal, v. 23, n. 2, p.310-314, $2001 b$.

TOTH, J.; MORRISON, G. Glyphosate drift damages fruit trees. The Agricultural Gazette of New South Wales, Sidney, v. 88, p. 44-45, 1977. 